\title{
Roles of the microRNA-338-3p/NOVA1 axis in retinoblastoma
}

\author{
SHOUBIN SUN ${ }^{1}$, RUNZE WANG $^{2}$, SISI YI $^{2}$, SIJIA $^{2}{ }^{2}$, LEI WANG $^{2}$ and JIANWEN WANG ${ }^{2}$ \\ ${ }^{1}$ Department of Ophthalmology, The Fourth Affiliated Hospital of Harbin Medical University; \\ ${ }^{2}$ Department of Ophthalmology, The First Affiliated Hospital of Harbin Medical University, \\ Harbin, Heilongjiang 150001, P.R. China
}

Received October 28, 2020; Accepted March 2, 2021

DOI: $10.3892 / \mathrm{mmr} .2021 .12033$

\begin{abstract}
Retinoblastoma (RB) is an intraocular malignancy that mainly affects young children. Previous reports have demonstrated that mutations or the inactivation of the RB1 gene were the main cause of RB; however, disruption of the intracellular signaling pathways following deficiency of RB1 requires further investigation. Based on the Gene Expression Omnibus data and bioinformatics prediction, the present study aimed to investigate the microRNA (miR)-338-3p/neuro-oncological ventral antigen 1 (NOVA1) axis in RB. Subsequently, overexpression and knockdown of miR-338-3p and NOVA1, respectively, were performed to study the role of miR-338-3p/NOVA1 in the progression of the RB cells. The results demonstrated that overexpression of miR-338-3p significantly inhibited cell proliferation, migration and invasion, and promoted apoptosis of the RB cells. Moreover, knockdown of NOVA1 showed similar results. A dual-luciferase reporter assay and rescue experiments further confirmed the direct binding between miR-338-3p and NOVA1. Taken together, the results indicated that miR-338-3p acted as tumor suppressor by targeting the oncogene of NOVA1 in $\mathrm{RB}$, which may serve as potential therapeutic targets in RB.
\end{abstract}

\section{Introduction}

Retinoblastoma (RB) is an intraocular malignancy affecting young children, with the majority of reported cases occurring before the age of 6 years old (1). The global incidence rate of RB is $\sim 1$ in 16,000-18,000 live births per year (2). Common clinical treatment strategies for RB include chemical volume reduction, intra-arterial and intravitreal chemotherapy, transpupillary thermotherapy, laser photocoagulation and scleral application radiotherapy (3). The development of precision medicine and tumor biological therapy, drugs or specific molecules that target key regulatory proteases in cells have shown effective

Correspondence to: Professor Jianwen Wang, Department of Ophthalmology, The First Affiliated Hospital of Harbin Medical University, 23 Youzheng Street, Nangang, Harbin, Heilongjiang 150001, P.R. China

E-mail: wangjw7709@163.com

Key words: microRNA-338-3p, neuro-oncological ventral antigen 1, retinoblastoma application prospects $(4,5)$. Due to the high rate of intracranial and distant metastasis of RB, which often endangers the lives of children, there is an urgent requirement to investigate the potential biological regulation mechanism of $\mathrm{RB}$ progression, thereby improving the cure rate and reducing the mortality rate.

Most cases of RB develop from a mutation or the inactivation of the RB1 tumor suppressor gene; however, the loss of RB1 function may directly or indirectly lead to the disruption of the intracellular signaling pathways, which ultimately leads to tumor progression $(2,6)$. As intracellular signaling pathways have been frequently associated with abnormal expression of microRNAs (miRNA/miR), this led to the hypothesis that miRNAs could be involved in RB development. As reported by previous studies, miRNAs are endogenous, conserved non-coding RNAs that are 19-22 nucleotides in length (7). The most well-known function of miRNA is to inhibit gene translation or induce subsequent mRNA degradation by binding to the 3'-untranslated region (3'-UTR) of their target mRNAs $(8,9)$. miRNAs are differentially expressed in tumor cells and have been associated with the occurrence and development of tumors $(10,11)$; therefore, differentially expressed miRNAs in RB (compared with those in healthy tissues or cells) in the Gene Expression Omnibus (GEO) database were investigated in the present study. The GEO database contains microarray, next-generation sequencing and other high-throughput sequencing data (12). From the GEO database, the GSE7072 dataset was used in the present study and it was found that miR-338-3p expression was significantly decreased in RB compared with that in healthy tissues. Previous studies revealed that miR-338-3p was a tumor suppressor gene, and was significantly decreased in non-small cell lung cancer (NSCLC), nasopharyngeal carcinoma and gastric cancer (13-15). However, to the best of our knowledge, the role of miR-338-3p in RB remains unknown. Thus, miR-338-3p and its potential downstream targets were investigated in the present study.

Among the results from bioinformatics target prediction, neuro-oncological ventral antigen 1 (NOVA1) was a gene of interest. NOVA1 is an RNA binding protein, which was found to affect cellular signal transduction and ligand-binding, as well as possesses ion channel electrophysiological properties (16). It has been reported that NOVA1 serves an important role in the occurrence and development of various diseases, including neurological diseases and tumors $(17,18)$. However, the mechanism of NOVA1 in RB remains to be determined. Thus, the present study aimed to identify the molecular mechanism of NOVA1 and the signaling pathway involved in RB. 


\section{Materials and methods}

Data collection and screening. The GSE7072 dataset from the GEO database was used to screen target miRNAs for the present research.

Cell culture. The human retinoblastoma (HXO-RB44, SO-RB50, Y79 and WERI-Rb-1) and the human retinal epithelial (ARPE-19) cell lines were purchased from the Chinese Academy of Sciences Cell Bank, and were cultured in DMEM, supplemented with 10\% FBS (all from Hyclone; Cytiva) at $37^{\circ} \mathrm{C}$ in a humidified incubator with $5 \% \mathrm{CO}_{2}$. The human retinal epithelial (ARPE-19) cell line, which was the cell line closest to the source of the human retinoblastoma cell lines (HXO-RB44, SO-RB50, Y79 and WERI-Rb-1), was used as the control. The reported literatures also used ARPE cells as the control of the Y79 cell line (19-21).

Tissue samples. The human retinoblastoma tissue samples were obtained from The First Affiliated Hospital of Harbin Medical University between April 2015 and September 2018. The RB tumor and healthy adjacent tissues were matched. The distance of healthy tissues from RB tissues was $2 \mathrm{~cm}$. All patients (age, 35-58 years; seven female patients and five male patients) were informed and agreed to the use of tissue samples. Ethics approval was obtained for the use of human tissues from the Ethics Committee of The First Affiliated Hospital of Harbin Medical University. The data were evaluated using a paired t-test.

Cell transfection. miR-338-3p mimics (agomir-338-3p) and the corresponding negative control (agomir-NC) (cat. no. miR40000763-4-5 for agomir-338-3p and cat. no. miR4N0000001-4-5 for agomir-NC) were purchased from Guangzhou RiboBio Co., Ltd. The pcDNA-NOVA1 and pcDNA-3.1 plasmids (cat. no. 4857 for pcDNA-NOVA1 and pcDNA-3.1 plasmids; Shanghai GeneChem Co., Ltd.) were constructed and purchased from Shanghai GeneChem Co., Ltd. Agomir-338-3p, agomir-NC, and the pcDNA-NOVA1 and pcDNA-3.1 plasmids were transfected into the Y79 and WERI-Rb-1 cells using Lipofectamine ${ }^{\circledR} 2000$ (cat. no. 11668027; Invitrogen; Thermo Fisher Scientific, Inc.) according to the manufacturer's instructions at $37^{\circ} \mathrm{C}$ for $48 \mathrm{~h}$. For the agomir-338-3p, agomir-NC and small interfering RNA (si)-NOVA1 or si-NC (Shanghai GeneChem Co., Ltd.) the amount used for transfection was 100 pmol. The sequences of si-NOVA1 were: Sense 5'-AGACAGAACCAGUCAGCAUTT-3' and antisense 5'-AUGCUGACUGGUUCUGUCUTT-3'. The sequences of si-NC were: Sense 5'-UUCUCCGAACGUGUCACGUTT-3' and antisense 5'-ACGUGACACGUUCGGAGAATT-3'. For the pcDNA-NOVA1 and pcDNA-3.1 plasmids, the amount used for transfection was $3 \mu \mathrm{g}$. The transfection was performed when the cell density reached $\sim 40 \%$. After the transfection was completed, the cells were cultured in a $37^{\circ} \mathrm{C}$ incubator for $48 \mathrm{~h}$. Transfection efficiency was determined using reverse transcription-quantitative PCR (RT-qPCR). The cells were collected for further experimentation at $48 \mathrm{~h}$ following transfection.

$R T-q P C R$. The extraction of total RNA from cells or tissues was performed using TRIzol $^{\circledR}$ (cat. no. 15596-026; Invitrogen; Thermo Fisher Scientific, Inc.) according to the manufacturer's instructions. First-strand cDNA was reverse transcribed from RNA $\left(37^{\circ} \mathrm{C}\right.$ for $15 \mathrm{~min}, 98^{\circ} \mathrm{C}$ for $\left.5 \mathrm{~min}\right)$ using the cDNA Synthesis kit (cat. no. 04897030001; Roche Diagnostics). For RT-qPCR analysis, the SYBR Green master mix (ROX) (cat. no. 04913914001; Roche Diagnostics) was used with a 7500 Fast Real-Time PCR system (Applied Biosystems; Thermo Fisher Scientific, Inc.) at the following thermocycling conditions: Initial denaturation $\left(95^{\circ} \mathrm{C}\right.$ for $10 \mathrm{~min}$; 40 cycles of denaturation $\left(95^{\circ} \mathrm{C}\right.$ for $15 \mathrm{sec})$, annealing $\left(60^{\circ} \mathrm{C}\right.$ for $\left.30 \mathrm{sec}\right)$ and elongation $\left(72^{\circ} \mathrm{C}\right.$ for $30 \mathrm{sec})$. GAPDH and U6 were used as the controls for mRNA and miRNA, respectively. All the primer sequences were designed and synthesized by Sangon Biotech Co., Ltd. The primer sequence used for qPCR was as follows: GAPDH forward, 5'-CAAGGTCATCCATGACAACTTTG-3' and reverse, 5'-GTCCACCACCCTGTTGCTGTAG-3'; U6 forward, 5'-CTCGCTTCGGCAGCACA-3' and reverse, 5'-AACGCTTCA CGAATTTGCGT-3'; miR-338-3p forward, 5'-TCCCCTAACT CCCAGTGTCT-3' and reverse, 5'-CTTGCCTTGGAGATTT GGG-3'; and NOVA1 forward, 5'-GGGTTCCCATAGACCTG GAC-3' and reverse, 5'-CGCTCAGTAGTACCTGGGTAA-3'. Relative gene differential expression was determined using the $2^{-\Delta \Delta \mathrm{Cq}}$ method (22). All experiments were repeated in triplicate.

Cell Counting Kit (CCK)-8 assay. The cells at a confluence of $60 \%$ in the logarithmic growth phase were cultured in 96-well plates at $37^{\circ} \mathrm{C}$ in a humidified incubator for $24 \mathrm{~h}$. Then, the cells in each well were incubated with $10 \mu \mathrm{l}$ CCK-8 solution (cat. no. C0037; Beyotime Institute of Biotechnology) for $1 \mathrm{~h}$ on a shaker according to the manufacturer's instructions. Following which, the absorbance value was measured at $450 \mathrm{~nm}$ using a microplate reader (Thermo Fisher Scientific, Inc.). The experiments were performed in triplicate.

Colony formation assay. The cells ( $400 /$ well) in the different treatment groups were seeded in 6-well plates and cultured for 2 weeks. Subsequently, each well of the cells was washed with PBS and fixed with $4 \%$ paraformaldehyde on ice for $15 \mathrm{~min}$. Then, $0.1 \%$ crystal violet was used to stain the cells at room temperature for $10 \mathrm{~min}$. Finally, images of the cells were captured using an optical camera (Olympus Corporation).

TUNEL assay. The TUNEL assay was performed using the one-step TUNEL cell apoptosis detection kit (cat. no. C1088; Beyotime Institute of Biotechnology) according to the manufacturer's instructions. In brief, the cells were fixed with $4 \%$ paraformaldehyde at room temperature for $30 \mathrm{~min}$ and washed with PBS. Then, the cells were incubated with $0.3 \%$ Triton X-100 in PBS for $5 \mathrm{~min}$ at room temperature. Following which, the cells were stained with the staining mixture from the one-step TUNEL cell apoptosis detection kit at room temperature for $30 \mathrm{~min}$. The cells in the sections were observed using a fluorescence microscope (Olympus Corporation) in six fields of view randomly selected under x200 magnification. The nuclei in the apoptotic cells were stained with DAPI $(10 \mu \mathrm{g} / \mathrm{ml}$, cat. no. C1002; Beyotime Institute of Biotechnology) at room temperature for $8 \mathrm{~min}$. The number of positive cells was calculated using ImageJ software (version 1.8.0; National Institutes of Health).

Western blot analysis. Total protein was extracted from the cells or tissues using RIPA buffer (cat. no. P0013C; Beyotime Institute 
of Biotechnology), which was mixed with protease inhibitors (Thermo Fisher Scientific, Inc.). The concentration of the total protein was quantified using a BCA assay (cat. no. PC0020-500; Beyotime Institute of Biotechnology). Then, 10\% SDS-PAGE was used to separate the proteins $(100 \mu \mathrm{g})$, which were subsequently transferred onto nitrocellulose membranes (cat. no. 88025; Thermo Fisher Scientific, Inc.) for $2 \mathrm{~h}$, at a current of $300 \mathrm{~mA}$. The membranes were blocked with $5 \%$ skimmed milk for $2 \mathrm{~h}$ at room temperature, then incubated with the following primary antibodies (all from Abcam) overnight at $4^{\circ} \mathrm{C}$ : NOVA1 (cat. no. ab183024; 1:1,000), Bax (cat. no. ab32503; 1:1,000), Bcl-2 (cat. no. ab182858; 1:1,000), cleaved-caspase-3 (cat. no. ab32042; 1:1,000), tubulin (cat. no. ab7291; 1:1,000), PI3K (cat. no. ab140307; 1:1,000), phosphorylated (p)-PI3K (cat. no. ab278545; 1:1,000), AKT (cat. no. ab8805; 1:1,000), p-AKT (cat. ab38449; 1:1,000). On the second day, the nitrocellulose membranes were incubated at room temperature for 45 min with the IRDye-labeled fluorescent secondary antibody (IRDye-conjugated Goat anti-Mouse IgG, cat. no. 926-32210; IRDye-conjugated Goat anti-Rabbit IgG, cat. no. 926-32211; LI-COR Biosciences; 1:8,000) according to the source of the primary antibody (rabbit or mouse). Subsequently, the bands on the membranes were visualized using an Odyssey infrared fluorescence scanning instrument (LI-COR Biosciences) and the detection of band gray value was performed using Image studio software (version 4.0; LI-COR Biosciences).

Cell migration and invasion assays. For the cell invasion assay, the upper chambers (BD Biosciences) were precoated with Matrigel (cat. no. 356234; BD Biosciences) at $37^{\circ} \mathrm{C}$ for $2 \mathrm{~h}$, then $5 \times 10^{4}$ cells were seeded in the upper chambers of the culture plate with Matrigel and cultured in serum-free medium. The lower chambers contained medium supplemented with $15 \% \mathrm{FBS}$. After incubation at $37^{\circ} \mathrm{C}$ for $24 \mathrm{~h}$, the cells that invaded to the lower surface of the chamber were fixed with $4 \%$ paraformaldehyde at room temperature for $20 \mathrm{~min}$, stained with $0.1 \%$ crystal violet at room temperature for $15 \mathrm{~min}$ and subsequently observed using an optical microscope (Olympus Corporation). For the cell migration assay, the cells $\left(5 \times 10^{4}\right.$ cells per well) were seeded in the upper chambers of the Transwell plate without Matrigel and the same protocol as the invasion assay was used. The cells were randomly selected from six fields of view using a confocal microscope (Olympus CX23; Olympus Corporation) at x200 magnification, then ImageJ software (version 1.8.0; National Institutes of Health) was used to calculate the number of invasive and migrated cells.

Dual-luciferase reporterassay. The Starbasev3.0 (http://starbase. sysu.edu.cn/) and the TargetScanv7.2 (http://www.targetscan. org/vert_72/) predictive databases were used to predict the potential targets of miR-338-3p in humans. Following bioinformatics prediction and screening, potential binding sites were identified between miR-338-3p and NOVA1. Therefore, a dual-luciferase reporter assay was performed to verify that miR-338-3p directly binds to NOVA1. Briefly, wild-type (wt) and mutant (mut) 3'-UTR of NOVA1 were cloned into the pmirGLO luciferase reporter vector (Guangzhou RiboBio Co., Ltd.). Subsequently, the Y79 and WERI-Rb-1 cells were co-transfected with wt-NOVA1 or mut-NOVA1 and 100 nM agomir-338-3p (Guangzhou RiboBio Co., Ltd.) or 100 nM agomir-NC Shanghai GeneChem Co.,
Ltd. using Lipofectamine ${ }^{\circledR} 2000$ (Invitrogen; Thermo Fisher Scientific, Inc.) at $37^{\circ} \mathrm{C}$ for $48 \mathrm{~h}$. Finally, luciferase activity was determined using the dual-luciferase reporter assay system (Promega Corporation) and normalized to Renilla luciferase activity.

Tumor xenograftmouse model. The animal study was performed in accordance with the Guide for the Care and Use of Laboratory Animals (National Research Council), and was approved by the Institutional Animal Care and Use Committee of Harbin Medical University (Heilongjiang, China). The mouse were kept under controlled conditions (temperature, $21^{\circ} \mathrm{C}$; humidity, $50-55 \%$ ) with a 12-h light/dark cycle, and free access to food and water. A mouse xenograft model was randomly established by subcutaneously injecting $1 \times 10^{6}$ Y 79 cells into 4-week-old female or male BALB/c nude mice (weight, 18-20 g) purchased from the Shanghai Laboratory Animal Center, CAS. A total of 9 mice were used as the NCs and 9 mice were assigned to the agomir-338-3p group. Then, the mice were injected intravenously (tail vein) with either agomir-338-3p or agomir-NC (10 nM). The tumor volumes were measured every 5 days following observation and were calculated using the following formula: Volume $=\left(\right.$ length $\mathrm{x}$ width $\left.{ }^{2}\right) / 2$. The maximum diameter of the tumor was $1.85 \mathrm{~cm}$ and the maximum volume was $1.85 \times 1.72 \times 1.5 \mathrm{~cm}$. A month later the mice were euthanized using isoflurane (induction, $3 \%$ and maintenance, $2 \%$ ). The duration of isoflurane exposure was within $5 \mathrm{~min}$. Death was confirmed by the observing breathing rate, the heartbeat, the pupils and the nerve reflex of the mouse. Finally, the tumor was removed for further experiments.

Immunohistochemistry. The tumor tissues were fixed with $4 \%$ paraformaldehyde at room temperature for $30 \mathrm{~min}$. After the transplanted tumor was paraffin-embedded and sliced into $0.5-\mu \mathrm{m}$ sections, immunohistochemistry analysis was performed. Briefly, the paraffin sections were dewaxed in xylene and rehydrated in a graded alcohol series (100, 95 and 80\%). Then, the sections were blocked with 5\% BSA (cat. no. ST025; Beyotime Institute of Biotechnology) at $37^{\circ} \mathrm{C}$ for $1 \mathrm{~h}$, and heated in a microwave oven in sodium citrate buffer $(0.1 \mathrm{mM}, \mathrm{pH} 6.0)$ for $5 \mathrm{~min}$ for antigen retrieval. Subsequently, the sections were incubated overnight at $4^{\circ} \mathrm{C}$ with a primary antibody against Ki67 (cat.no. ab15580; 1:1,000; Abcam). Following which, the sections were incubated with a secondary antibody (cat. no. ab205718; 1:2,000; Abcam) at $37^{\circ} \mathrm{C}$ for $1 \mathrm{~h}$. The sections were then stained with diaminobenzidine at room temperature for 3-15 min and counterstained with hematoxylin at room temperature for $5 \mathrm{~min}$. Finally, the images were captured using an Olympus light microscope (Olympus Corporation) under x200 magnification.

Statistical analysis. All the data are presented as the mean \pm SEM from three independent experiments. The software used for statistical analysis was GraphPad Prism 5 (version 5.01; GraphPad Software, Inc.). Statistical analysis between two groups was performed using an unpaired Student's t-test, while in the analysis of miR-338-3p expression levels in RB tumor and adjacent tissues, the data were analyzed with a paired t-test. One-way ANOVA followed by Tukey's post hoc test was performed when comparing $>2$ groups. $\mathrm{P}<0.05$ was considered to indicate a statistically significant difference. 

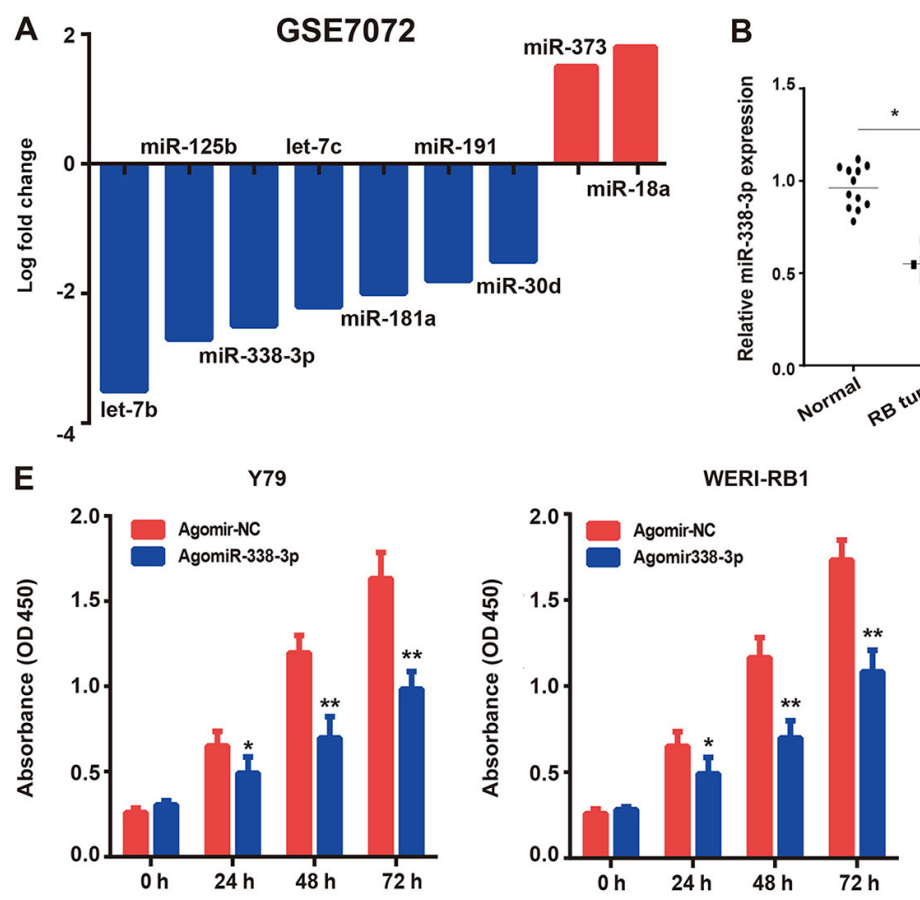

G
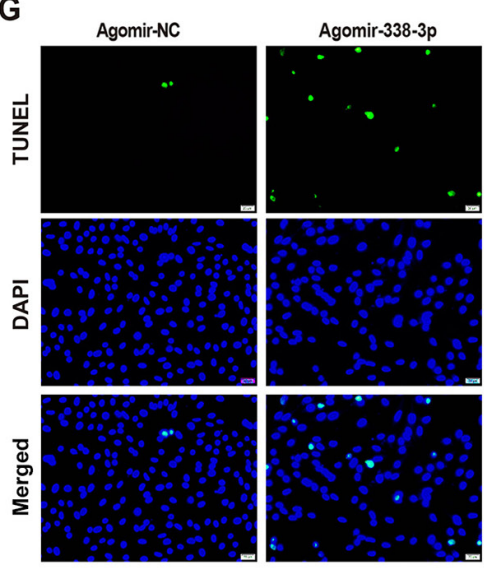

Y79

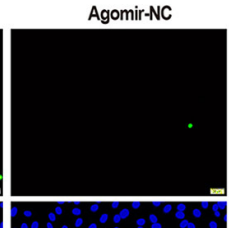

Agomir-338-3p

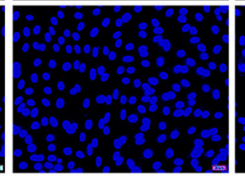

B

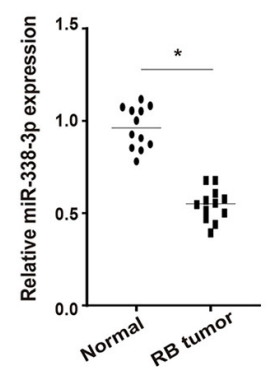

WERI-RB

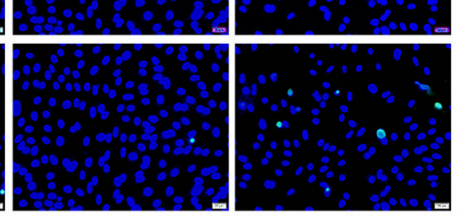

WERI-RB1
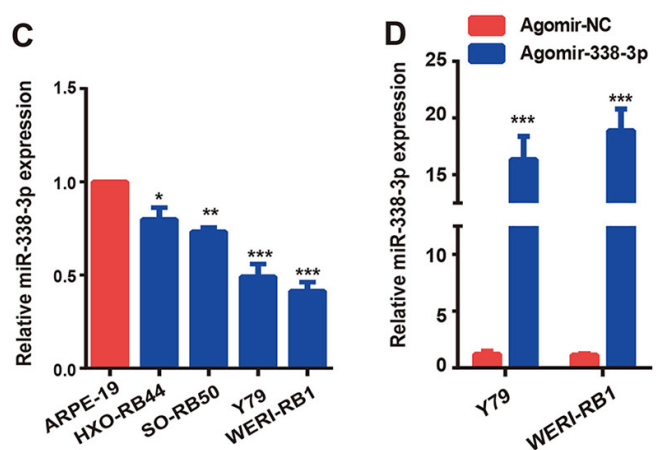

$F$
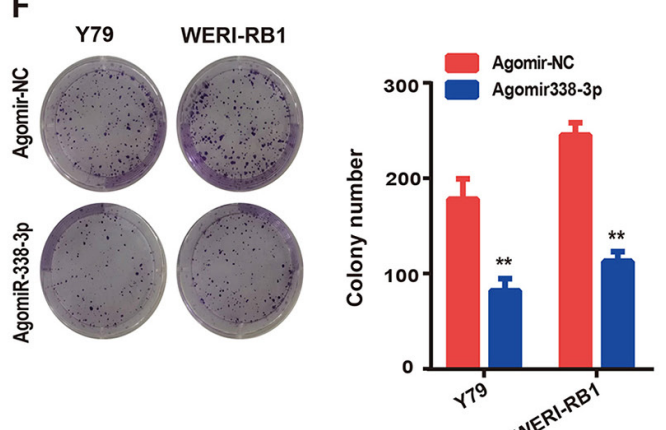

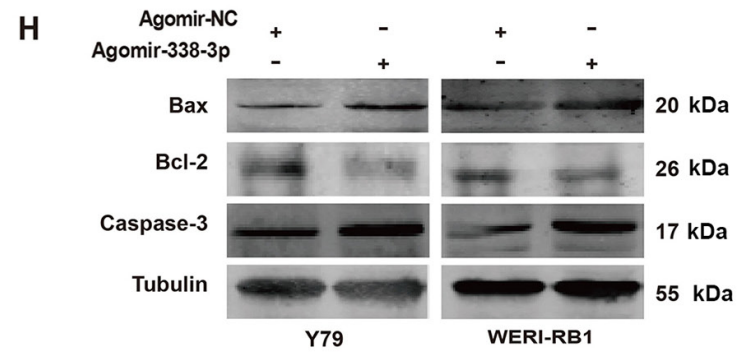

Figure 1. Roles of miR-338-3p in the RB cell lines. The expression levels of (A) miRNAs in the RB tissues from the GSE7072 dataset. miR-338-3p expression levels in (B) RB tissues compared with normal tissues, and (C) in the human RB (HXO-RB44, SO-RB50, Y79 and WERI-Rb-1) cells compared with the normal human retinal epithelial (ARPE-19) cell lines. (D) Transfection efficiency of miR-338-3p mimics was confirmed using reverse transcription-quantitative PCR. Overexpression of miR-338-3p inhibited the (E) proliferation and (F) colony formation ability of the Y79 and WERI-Rb-1 cells, as determined using Cell Counting Kit- 8 and colony formation assays, respectively. (G) Overexpression of miR-338-3p increased the rate of apoptosis in the Y79 and WERI-Rb-1 cells, as determined using a TUNEL assay (x200 magnification). (H) Western blot analysis was used to analyze the protein expression levels of the apoptosis-related proteins. The data are presented as the mean \pm SEM from $\geq 3$ independent experiments. ${ }^{*} \mathrm{P}<0.05,{ }^{* *} \mathrm{P}<0.01$ and ${ }^{* * * *} \mathrm{P}<0.001$ vs. ARPE-19 cells or agomir-NC. $\mathrm{RB}$, retinoblastoma; miRNA/miR, microRNA; NC, negative control; OD, optical density.

\section{Results}

Expression levels of miR-338-3p and possible roles in the $R B$ cell lines. First, the GEO database was used to identify differentially expressed miRNAs in RB cases compared with those in normal tissues or retinal epithelial cells. Notably, in the GSE7072 dataset, it was found that miR-338-3p expression was significantly decreased in RB compared with that in normal tissues (Fig. 1A). However, the role of miR-338-3p in $\mathrm{RB}$ remains unknown. To further confirm the expression 

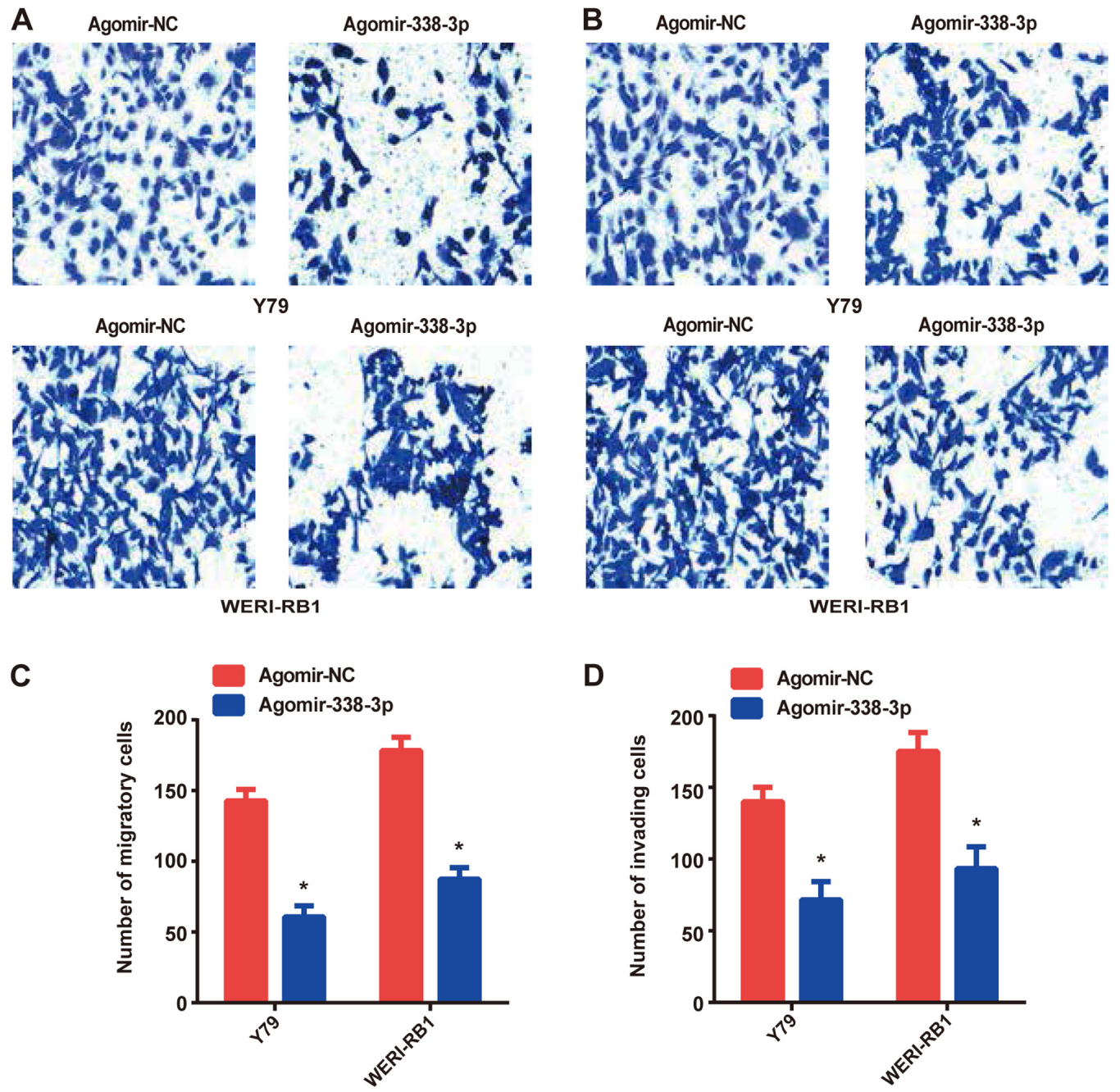

Figure 2. Effect of miR-338-3p on the migration and invasion of RB cells. (A) Representative images of the migration of the Y79 and WERI-Rb-1 cells, which was assessed using a Transwell assay (x200 magnification). (B) Representative images of the invasion of the Y79 and WERI-Rb-1 cells, which was evaluated using a Matrigel assay (x200 magnification). (C) Statistical analysis of cell migration. (D) Statistical analysis of cell invasion. The data are presented as the mean \pm SEM from $\geq 3$ independent experiments. ${ }^{*} \mathrm{P}<0.05$ vs. agomir-NC. RB, retinoblastoma; miR, microRNA; NC, negative control.

of miR-338-3p in RB tissues and cell lines, RT-qPCR was performed. It was found that the expression level of miR-338-3p in human RB tissues was lower compared with that in normal tissues (Fig. 1B). Similarly, the expression levels of miR-338-3p in the human RB cell lines (HXO-RB44, SO-RB50, Y79 and WERI-Rb-1) were downregulated (Fig. 1C), compared with those in the normal human retinal epithelial cells (ARPE-19). The Y79 and WERI-Rb-1RB cell lines were selected for further experiments, as there was a notably lower expression level of miR-338-3p compared with the other cell lines.

To determine the role of miR-338-3p in RB cells, miR-338-3p was overexpressed in the Y79 and WERI-Rb-1 cells by transfecting them with agomir-338-3p. The transfection efficiency was confirmed using RT-qPCR (Fig. 1D). After the overexpression of miR-338-3p, cell proliferation and apoptosis were investigated, as well as the expression levels of related protein markers. As shown in Fig. 1E and F, overexpression of miR-338-3p significantly inhibited Y79 and WERI-Rb-1 cell proliferation, compared with that observed in cells transfected with agomir-NC, as detected using CCK-8 and colony formation assays. Conversely, the apoptotic ratio of the Y79 and WERI-Rb-1 cells was significantly elevated in the agomir-338-3p group (Fig. 1G). In addition, the expression levels of several key regulatory proteins in the apoptosis signaling pathway were determined using western blot analysis, and the results (Fig. $1 \mathrm{H}$ ) were consistent with cell apoptosis analysis. The aforementioned results suggested that miR-338-3p may act as a tumor suppressor in the RB cells.

Overexpression of $m i R-338-3 p$ inhibits the migration and invasion of $R B$ cells. Transwell and Matrigel assays were performed to investigate the migratory and invasive abilities of the RB cells, respectively. Compared with the agomir-NC group, overexpression of miR-338-3p (agomir-338-3p group) significantly suppressed the migratory and invasive abilities of Y79 and WERI-Rb-1 cells (Fig. 2).

Target gene of miR-338-3p. The binding sites between miR-338-3p and the 3'-UTR of NOVA1 mRNA were predicted using the Starbasev3.0 and TargetScan online databases (Fig. 3A), which indicated that NOVA1 was a potential target gene of miR-338-3p. To confirm the binding sequences between miR-338-3p and NOVA1, a dual-luciferase reporter assay was performed. The binding sites of miR-338-3p with 


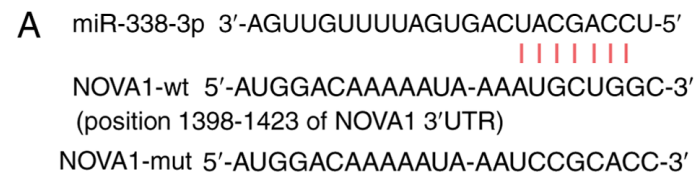

B

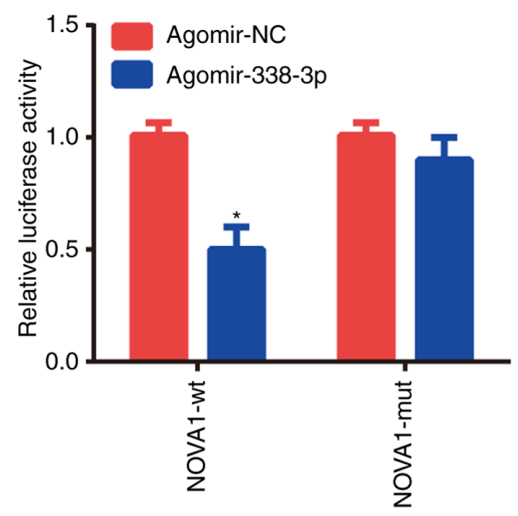

C

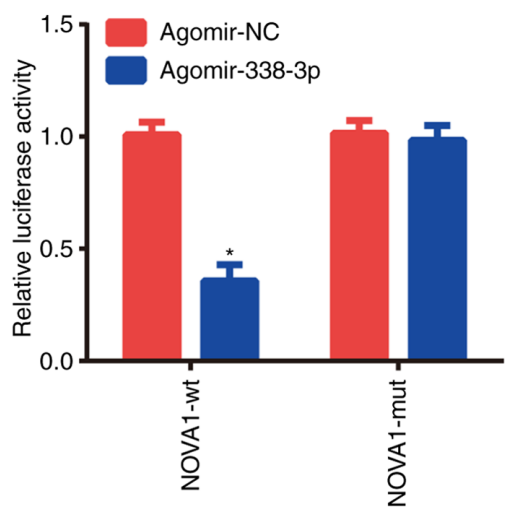

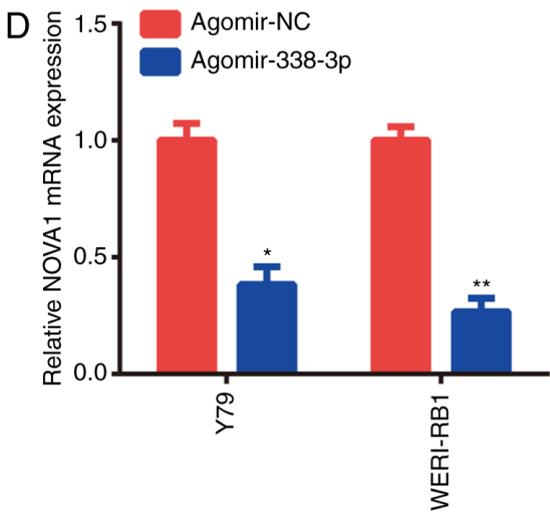

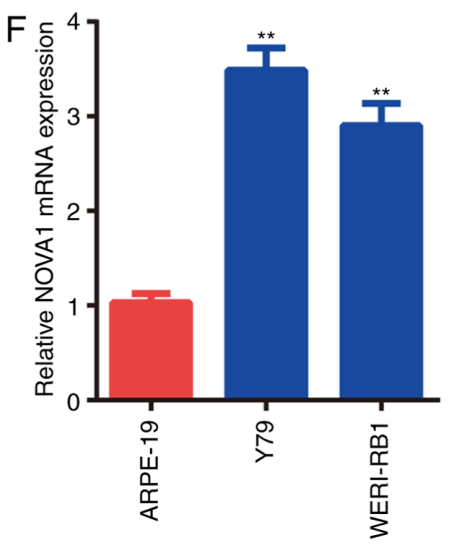

$\mathrm{E}$

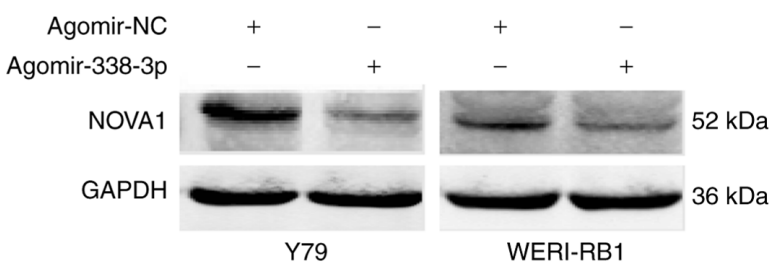

G

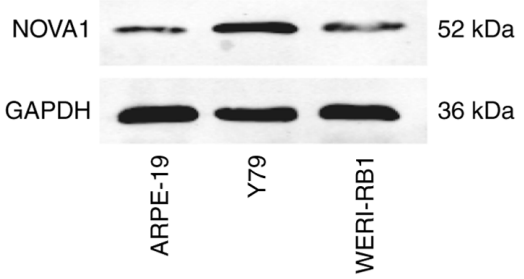

Figure 3. Target gene of miR-338-3p and its expression level in the RB cell lines. (A) Bioinformatics analysis predicted the binding sites between the 3'-UTR of NOVA1 and miR-338-3p. The binding sites between NOVA1 and miR-338-3p were verified using a dual-luciferase assay in the (B) Y79 and (C) WERI-Rb-1 cells. The effect of miR-338-3p on the (D) mRNA and (E) protein expression levels of NOVA1. The mRNA and protein expression levels of NOVA1 in the (F) Y79 and $(\mathrm{G})$ WERI-Rb-1 cells. The data are presented as the mean \pm SEM from $\geq 3$ independent experiments. ${ }^{*} \mathrm{P}<0.05$ and ${ }^{* * *} \mathrm{P}<0.01$ vs. ARPE-19 or agomir-NC. RB, retinoblastoma; miR, microRNA; NOVA1, neuro-oncological ventral antigen 1; NC, negative control; wt, wild-type; mut, mutant; UTR, untranslated region.

the position 1,398-1,423 of NOVA1 3'-UTR were used. The results demonstrated that overexpression of miR-338-3p suppressed luciferase activity in the Y79 and WERI-Rb-1 cells co-transfected with the reporter plasmid containing the wt 3'-UTR of NOVA1 and agomir-338-3p (Fig. 3B and C). However, agomir-338-3p had no effect on luciferase activity when the cells were transfected with the reporter plasmid containing the MUT 3'-UTR of NOVA1.
It was found that overexpression of miR-338-3p could notably decrease the mRNA (Fig. 3D) and protein (Fig. 3E) expression levels of NOVA1. As the expression levels of miR-338-3p were lower in the Y79 and WERI-Rb-1 cells compared with those in the ARPE-19 cells, it was hypothesized that the expression levels of NOVA1 would be increased. Subsequently, it was found that the mRNA (Fig. 3F) and protein (Fig. 3G) expression levels of NOVA1 were significantly higher in the Y79 

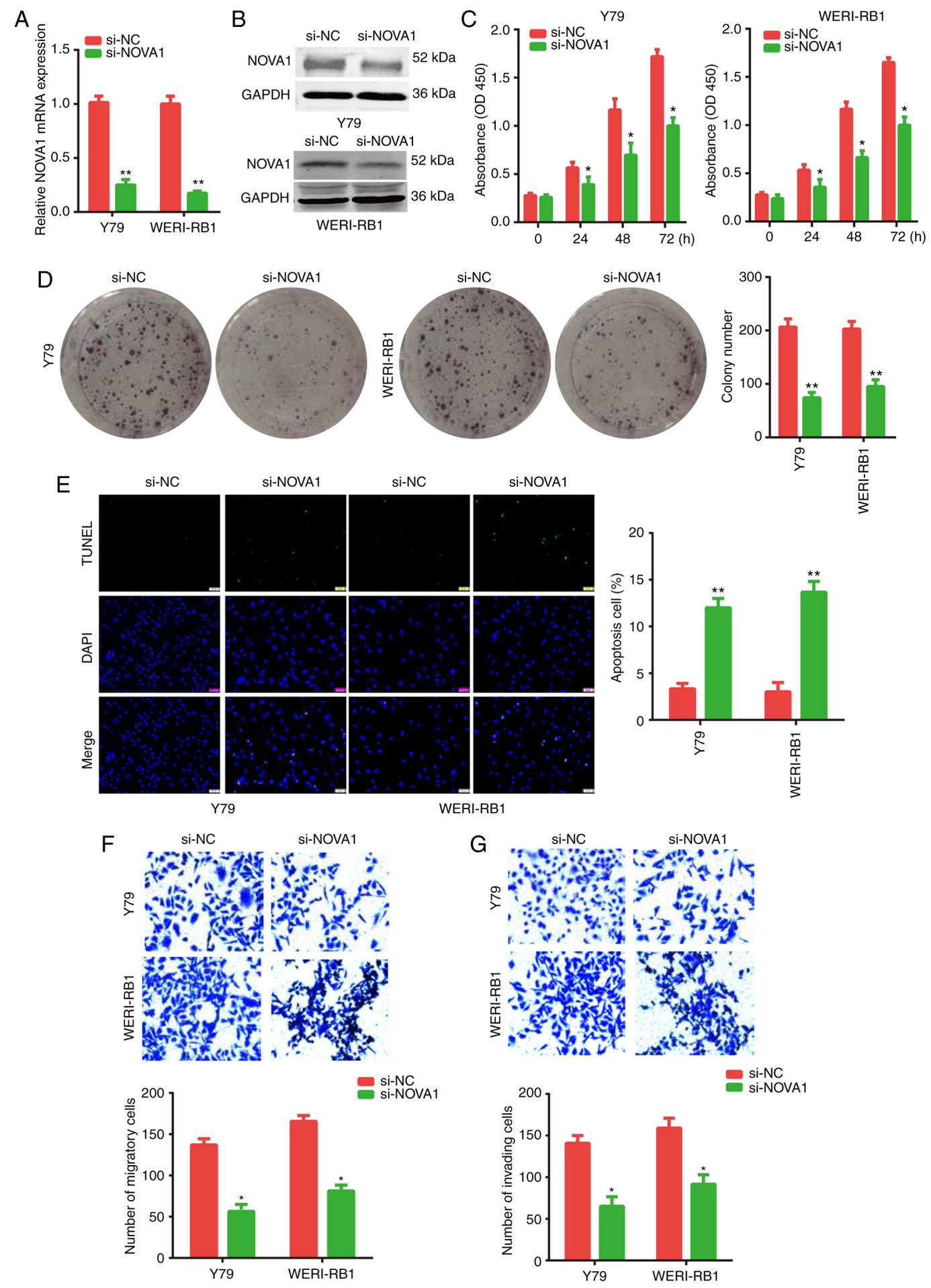

Figure 4. Effect of NOVA1 knockdown on the cell biological activities of the RB cell lines. (A) Reverse transcription-quantitative PCR and (B) western blot analysis were performed to determine the knockdown efficiency of NOVA1. Knockdown of NOVA1 significantly inhibited the proliferation of the (C) Y79 and (D) WERI-Rb-1 cells, and was determined using Cell Counting Kit-8 and colony formation assays, respectively. (E) Knockdown of NOVA1 significantly increased the rate of apoptosis of both the Y79 and WERI-Rb-1 cells determined by TUNEL (x200 magnification). Knockdown of NOVA1 significantly suppressed the (F) migratory and (G) invasive abilities of both the Y79 and WERI-Rb-1 cells (x200 magnification). The data are presented as the mean \pm SEM from $\geq 3$ independent experiments. ${ }^{*} \mathrm{P}<0.05$ and ${ }^{* *} \mathrm{P}<0.01$ vs. si-NC. RB, retinoblastoma; NOVA1, neuro-oncological ventral antigen 1; NC, negative control; si, small interfering RNA; OD, optical density.

and WERI-Rb-1 cells compared with those in the ARPE-19 cells. These data suggested that NOVA1 was a direct target of miR-338-3p.

Knockdown of NOVA1 on the biological activities of the $R B$ cells. As the expression level of endogenous NOVA1 was increased in the RB cells, NOVA1 expression was knocked down by transfecting the Y79 or WERI-Rb-1 cells with si-NOVA1. Subsequently, various biological activities of the cells were investigated. The knockdown efficiency of NOVA1 was determined using RT-qPCR (Fig. 4A) and western blotting (Fig. 4B). Further analysis revealed that 
knockdown of NOVA1 significantly inhibited the proliferation of the Y79 and WERI-Rb-1 cells, which was determined using CCK-8 (Fig. 4C) and colony formation assays (Fig. 4D). As shown in Fig. 4E, knockdown of NOVA1 significantly increased the apoptotic rate of both the Y79 and WERI-Rb-1 cells. The Transwell assay also confirmed that the NOVA1 gene may be an oncogene, as the migratory and invasive abilities of the Y79 and WERI-Rb-1 cells were significantly suppressed (Fig. 4F and G) following knockdown of NOVA1. These findings indicated that NOVA1 may act as an oncogene and serve a pivotal role in the progression of RB cells.

Co-transfection of agomir-338-3p and pcNOVA1 plasmid counteract each other. According to the aforementioned results, it was suggested that the miR-338-3p/NOVA1 axis may serve an important role in the progression of $\mathrm{RB}$. Thus, rescue experiments were performed by co-transfecting agomir-338-3p and pcNOVA1 plasmid into the Y79 and WERI-Rb-1 cells. The efficiency of overexpression of NOVA1 was verified via RT-qPCR and western blot analysis (Fig. S1). The results demonstrated that the decrease in NOVA1 mRNA (Fig. 5A) and protein (Fig. 5B) expression levels, following overexpression of agomir-338-3p, were rescued when the NOVA1 overexpression plasmid (pcNOVA1) was co-transfected into Y79 and WERI-Rb-1 cells. Similarly, the induced changes in cell proliferation (Fig. 5C), apoptosis (Fig. 5D), migration (Fig. 5E) and invasion (Fig. 5F), following overexpression of agomir-338-3p, were all partially reversed by the co-transfection of the pcNOVA1 plasmid.

Subsequently, the expression levels of several key regulatory proteins in the apoptosis signaling pathway were determined using western blot analysis, and the results were consistent with the results from the cell apoptosis experiments (Fig. 6A). Overexpression of miR-338-3p increased the rate of cell apoptosis. With regards to protein expression levels, there was a decrease in the expression levels of Bcl-2, and an increase in the expression levels of Bax and cleaved caspase-3 in the agomir-338-3p group compared with those in the agomir-NC group. In addition, as PI3K and AKT are known as anti-apoptotic protein markers (23), the expression levels of PI3K and AKT were also detected. The results demonstrated that the expression levels of PI3K and AKT were decreased in the agomir-338-3p group (Fig. 6B), which was consistent with the increased level of apoptosis. Furthermore, all of the miR-338-3p-induced protein alterations could be partially reversed by the overexpression of NOVA1. Taken together, it was indicated that the miR-338-3/NOVA1 axis may serve an oncogenic role in the progression of the $\mathrm{RB}$ cells.

Overexpression of miR-338-3p inhibits RB tumor progression in vivo. To validate the aforementioned results in vivo, nude mice were injected with the Y79 cells to establish xenograft RB tumors. Then, the mice were injected intravenously with either agomir-338-3p or agomir-NC. The tumor volumes were measured every 5 days after the outline of the tumors were observed. A month later, all the mice were sacrificed under anesthesia and the tumor was removed for further analysis. As presented in Fig. 7A, compared with that in the agomir-NC group, overexpression of miR-338-3p significantly inhibited the growth of the RB tumor, as determined by visual tumor size (Fig. 7A), tumor volume (Fig. 7B) and weight (Fig. 7C). In addition, the results of immunohistochemistry identified that overexpression of miR-338-3p inhibited the expression level of Ki67 (Fig. 7D), which indicated that the proliferation of the tumor cells was decreased. The expression levels of NOVA1 in the xenograft tumors were also downregulated following overexpression of miR-338-3p (Fig. 7D), which was consistent with the results of the in vitro experiments. Furthermore, the expression levels of miR-338-3p in the xenograft tumors after agomir-338-3p transfection were confirmed using RT-qPCR (Fig. 7E). The expression levels of PI3K and AKT were detected using western blot analysis, and the results (Fig. 7F and $\mathrm{G}$ ) indicated that overexpression of miR-338-3p inhibited the expression levels of PI3K and AKT (in the phosphorylation state), suggesting that the growth of the tumor was inhibited. Consistent with the results obtained from the RB cell lines, overexpression of miR-338-3p in the xenograft tumors inhibited the expression levels of NOVA1. The in vivo results further demonstrated the tumor suppressor role of miR-338-3p in the RB cells.

\section{Discussion}

It is well-known that RB is a common infant retinal cancer, which develops when both RB1 alleles are mutated or have a loss of function (6). Moreover, the occurrence and further progression of $\mathrm{RB}$ requires additional epigenetic dysregulation, following the inactivation of the RB1 protein, which manifests as the disruption of multiple signaling pathways in the tumor cells (24). The epigenetic dysregulation in RB includes abnormal histone modifications, DNA methylation or acetylation and non-coding RNAs (25). With regards to non-coding RNAs, aberrant non-coding RNA expression in RB tumorigenesis and progression has been reported $(21,26,27)$. While aberrant non-coding RNAs may not be the initial cause of $\mathrm{RB}$, the progression of $\mathrm{RB}$ has been associated with these molecular alterations.

In recent years, a large number of miRNAs have been reported to serve as tumor suppressors or oncogenes in tumor cells. For instance, miR-338-3p has been discovered to be a tumor suppressor in numerous types of cancer, such as NSCLC, nasopharyngeal carcinoma and gastric cancer (13-15). As the expression level of miR-338-3p in RB was downregulated in the GEO database, which was consistent with different types of cancer examined in previous studies $(28,29)$, it was suggested that miR-338-3p could be a tumor suppressor. Thus, we hypothesized that miR-338-3p may also be a tumor suppressor in RB. Combined with the prediction from bioinformatics analysis, it was found that the oncogene, NOVA1, was the downstream target gene of miR-338-3p. Thus, the present study aimed to further examine the miR-338-3p/NOVA1 axis and its role in $\mathrm{RB}$ progression. It was identified that the expression level of miR-338-3p was increased in both RB tissues (compared with that in normal tissues) and cell lines. Overexpression of miR-338-3p notably inhibited the viability of the RB cells, induced cell apoptosis and suppressed the migratory and invasive abilities. In addition, the RB cells with decreased NOVA1 expression level exhibited a similar phenotype to cells with miR-338-3p overexpression. The effects of agomir-338-3p on the RB cells were partially reversed by NOVA1 overexpression 

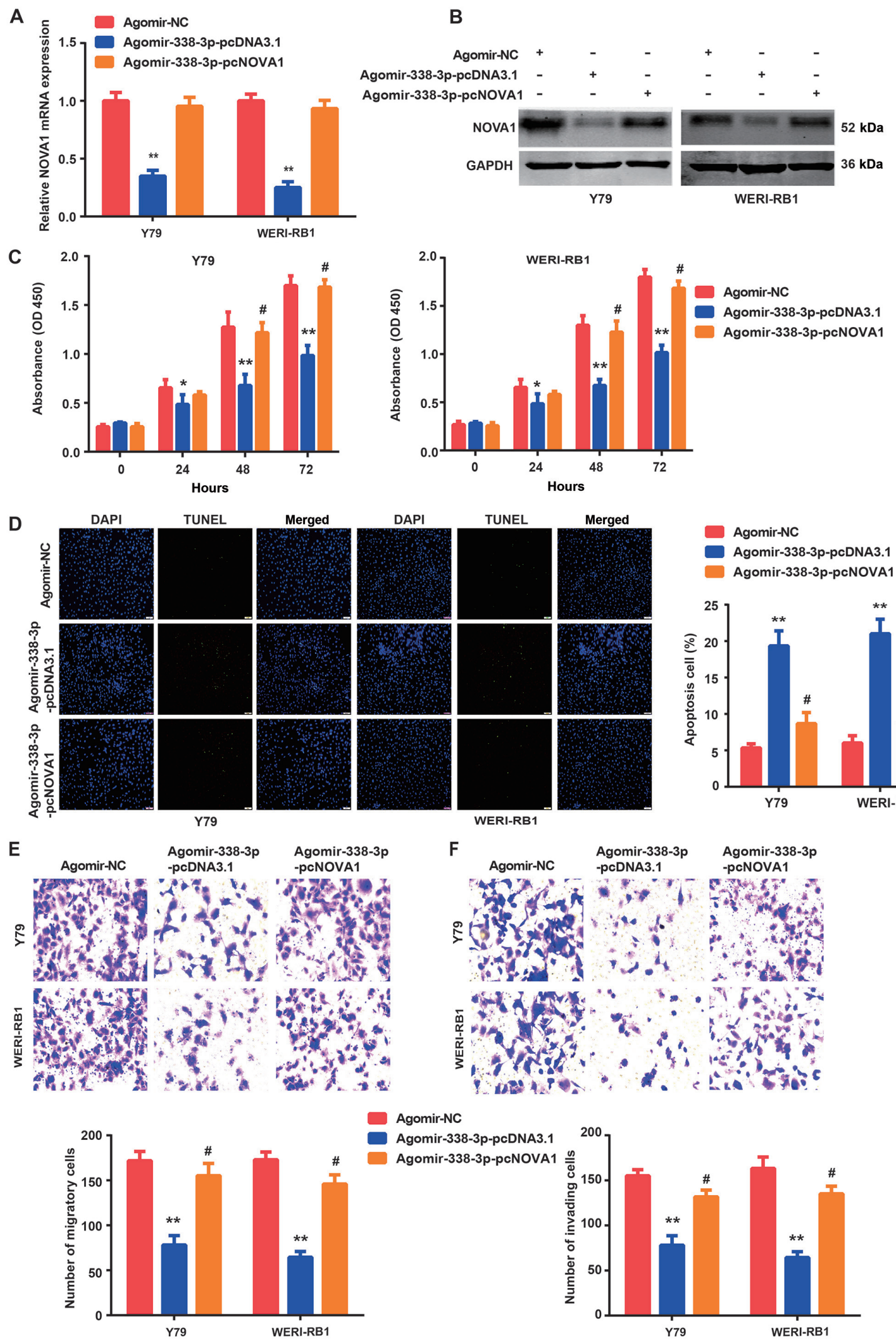

Figure 5. Rescue experiments. Co-transfection of agomir-338-3p and pcNOVA1 plasmid reversed the (A) mRNA and (B) protein expression levels of NOVA1. pcNOVA1 partially reversed the (C) decrease in cell proliferation and (D) increase in cell apoptosis (TUNEL assay, $x 200$ magnification) induced by agomir-338-3p. pcNOVA1 partially reversed the decrease in (E) cell migration and (F) invasion induced by agomir-338-3p (x200 magnification). The data are presented as the mean \pm SEM from $\geq 3$ independent experiments. ${ }^{*} \mathrm{P}<0.05$ and ${ }^{* *} \mathrm{P}<0.01$ vs. agomir NC; ${ }^{*} \mathrm{P}<0.05$ vs. agomir-338-3p-pcDNA3.1. RB, retinoblastoma; miR, microRNA; NOVA1, neuro-oncological ventral antigen 1; NC, negative control; OD, optical density.

plasmid. Mechanistically, the downstream target gene of miR-338-3p, NOVA1, was demonstrated to be responsible for the regulation of the aforementioned cellular activities. In addition, the expression levels of several proteins associated 

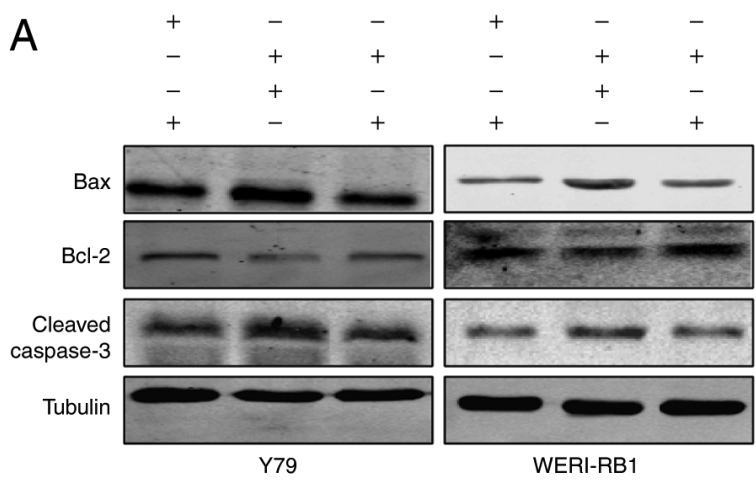

Agomir-NC
Agomir-338-3p
pc-DNA3.1
pC-NOVA1
$20 \mathrm{kDa}$
$26 \mathrm{kDa}$
$17 \mathrm{kDa}$
$55 \mathrm{kDa}$

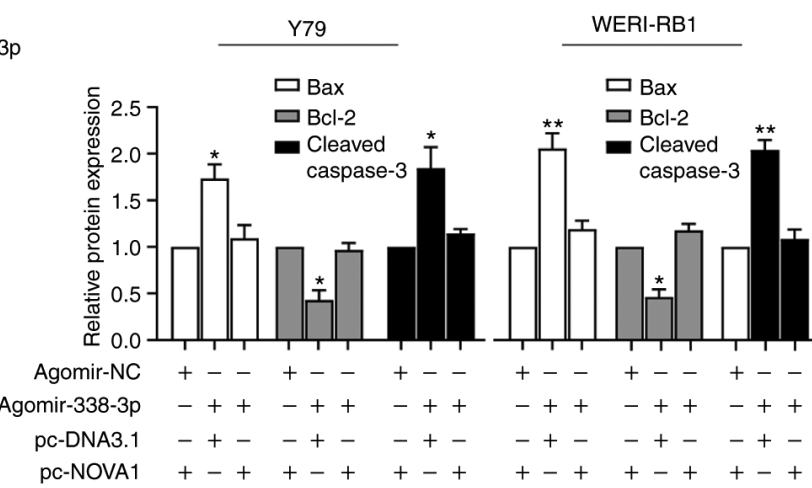

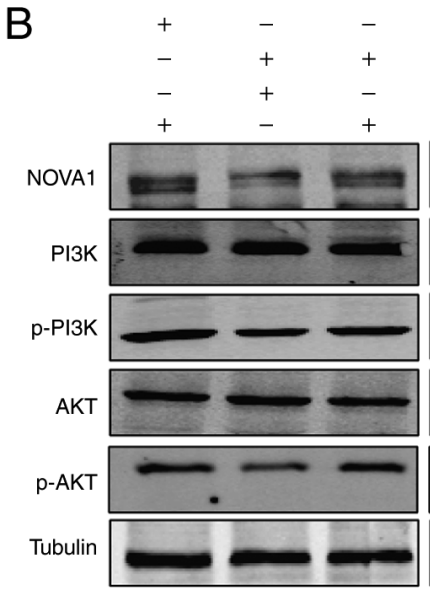

Y79

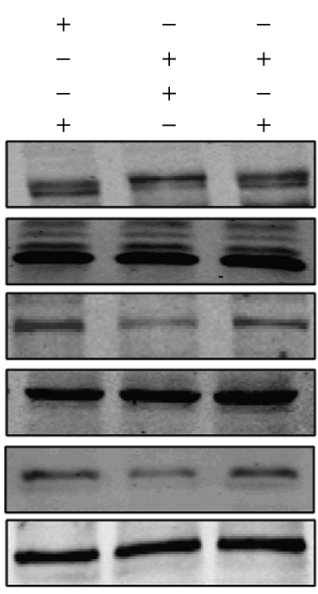

WERI-RB1
Agomir-NC

Agomir-338-3p

pc-DNA3.

pc-NOVA1

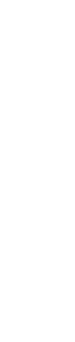
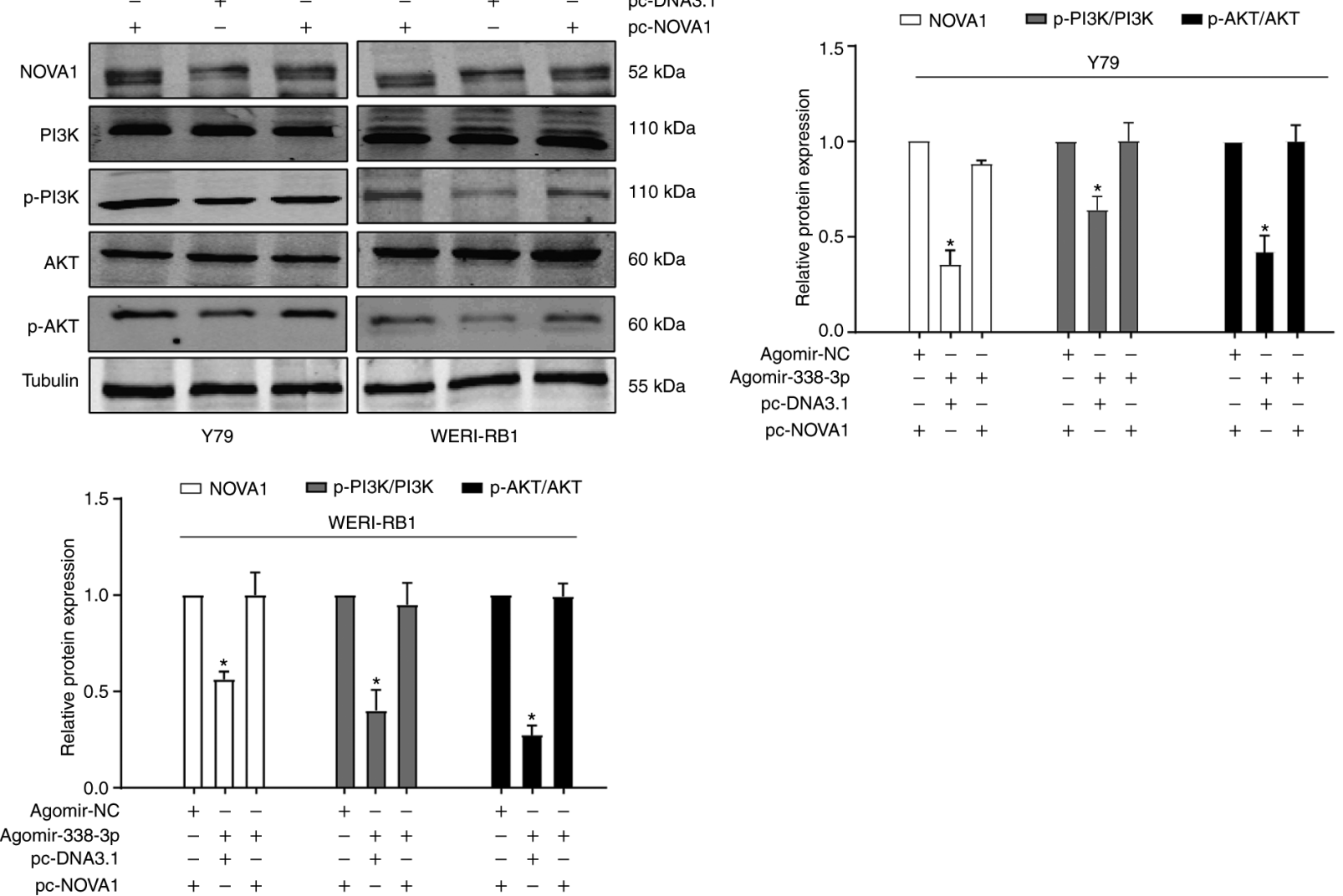

Figure 6. Expression levels of apoptosis and anti-apoptotic pathway proteins. (A) The expression levels of key regulatory proteins in the apoptosis signaling pathway, including Bcl-2, Bax and cleaved-caspase-3. (B) The expression levels of key regulatory proteins in the anti-apoptosis signaling pathway, including PI3K, p-PI3K, AKT and p-AKT. All experiments were repeated in three independent experiments. ${ }^{*} \mathrm{P}<0.05$ and ${ }^{* *} \mathrm{P}<0.01$ vs. agomir-338-3p-pc-NOVA1. p, phosphorylated; miR, microRNA; NOVA1, neuro-oncological ventral antigen 1; NC, negative control.

with cell proliferation and apoptosis were determined in vivo and in vitro; however, there was no direct evidence that the miR-338-3p/NOVA1 axis could directly regulate the function or expression level of these proteins, although the present study provided evidence that overexpression of miR-338-3p or NOVA1 could cause changes in the expression of these proteins.

Accumulating evidence has reported the function of RB1 in $\mathrm{RB}(24,30,31)$. The main research goal of the present study was to investigate the role of the miR-338-3p/NOVA1 axis in $\mathrm{RB}$. Whether the alteration of the miR-338-3p/NOVA1 axis was associated with $\mathrm{RB} 1$ required further examination. In the current study, the relevance of the miR-338-3/NOVA1 axis to the RB1 gene was not determined. One possibility is that NOVA1 is a protein that can alternatively splice the mRNA of certain genes, including oncogenes $(32,33)$. After the expression level of NOVA1 is increased (for example, in an environment of low miR-338-3p expression), the variable splicing mode of the genes regulated by NOVA1 changes, which eventually leads to the disorder of the cell signaling pathway (34).

A limitation of the present was that there were no experiments to examine all the upstream and downstream proteins associated with cell apoptosis, as well as the signal pathways associated with cell proliferation, migration and invasion. Furthermore, in the in vivo xenograft tumor experiment, only 
A
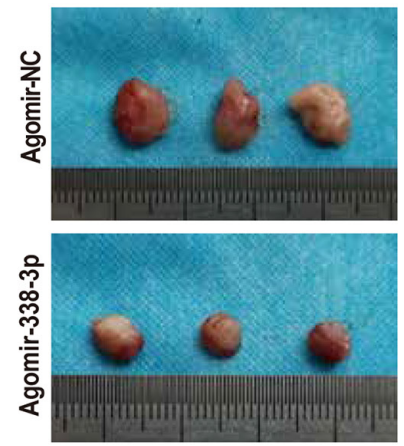

B

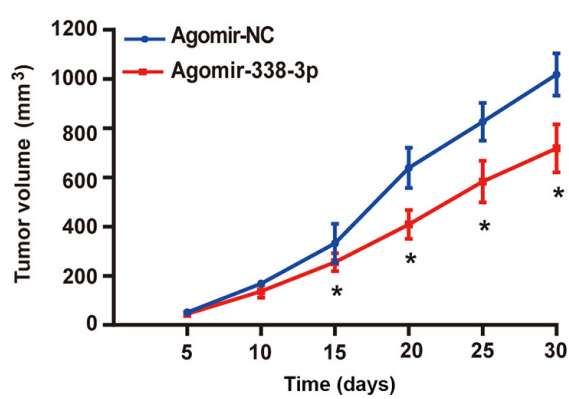

C

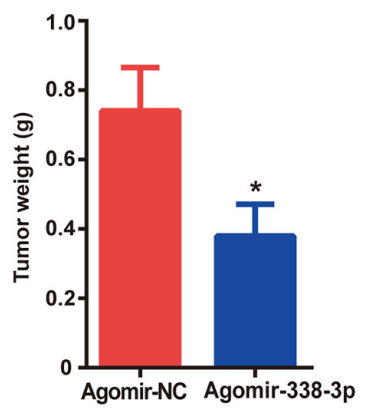

D
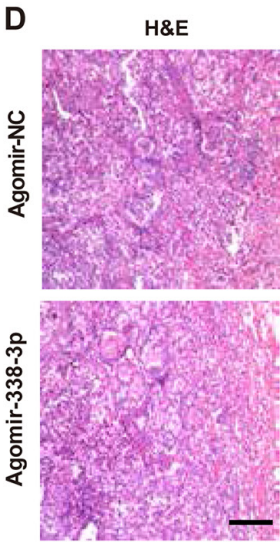

Ki67
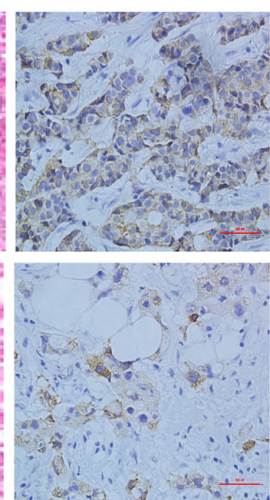

NOVA1
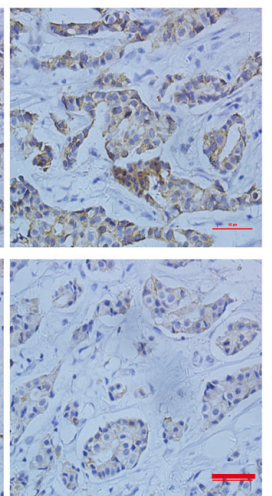

E

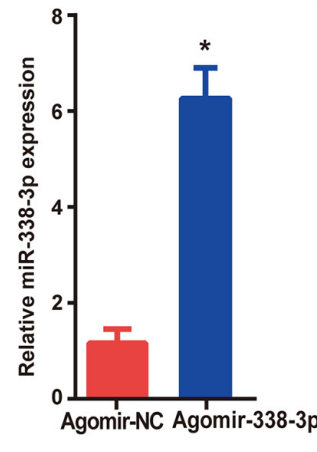

F Agomir-NC + Agomir-338-3p

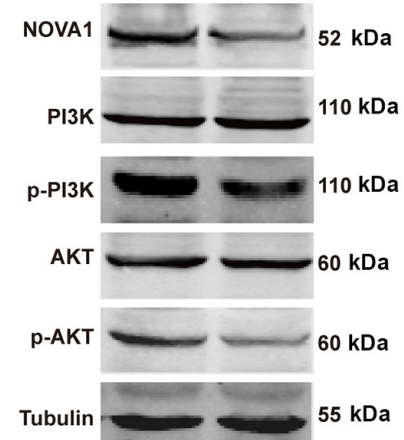

G

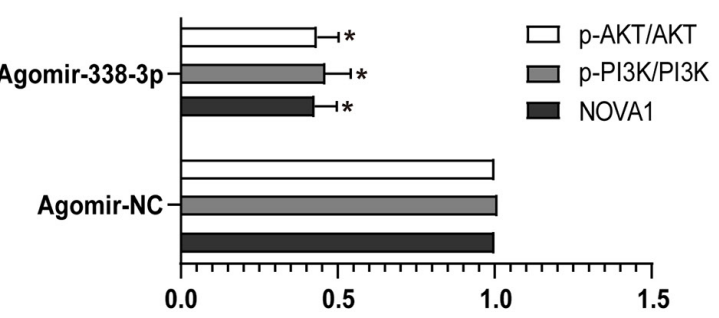

Figure 7. Overexpression of miR-338-3p inhibits RB tumor progression in vivo. (A) Representative images of the xenograft tumors treated with agomir-338-3p or agomir-NC. Tumor (B) volume and (C) weight in the mice treated with agomir-338-3p or agomir-NC. (D) H\&E staining of the tumors (first column), and the expression levels of Ki67 and NOVA1 determined using immunohistochemistry (x200 magnification). The scale bars represent $50 \mu \mathrm{m}$ for H\&E, and $100 \mu \mathrm{m}$ for immunostained images. (E) Expression level of miR-338-3p in the xenograft tumors treated with agomir-338-3p or agomir-NC. (F) Western blotting results of the $(\mathrm{G})$ expression levels of key regulatory proteins in the anti-apoptosis signaling pathway, including PI3K, p-PI3K, AKT and p-AKT. The data are presented as the mean \pm SEM from $\geq 3$ independent experiments. ${ }^{*} \mathrm{P}<0.05$ vs. agomir-NC. miR, microRNA; , phosphorylated; NC, negative control; NOVA1, neuro-oncological ventral antigen 1.

the effect of miR-338-3p on RB tumors was confirmed. Due to the technical difficulty of knocking down NOVA1 in the mice, there was a lack of NOVA1 knockdown experiments in vivo. Moreover, due to the limitations of experimental equipment, conditions and technical level, the present study was currently unable to establish orthotopic mouse models. Thus, the establishment of xenotransplantation mouse model (Y-79 cells subcutaneously injected into mice) is permitted and reasonable $(35,36)$. These limitations in the present study require further investigation.

Although the previous published literature has proved the role of NOVA1 in RB (37), the underlying molecular mechanism remains unknown and needs to be verified by in vivo animal experiments. The present study provided evidence that the miR-338-3p/NOVA1 axis serves a key regulatory role in various activities of $\mathrm{RB}$ through in vivo and in vitro experiments. To the best of our knowledge, this was the first time that it has been confirmed in RB that miR-338-3p is a tumor suppressor gene. Due to the complexity of the regulatory pathways inside the cell, other proteases or molecules are also reported to regulate the progress of $\mathrm{RB}$, including long non-coding RNA (38) and circular RNA (39). These factors ultimately led to changes in miRNAs. Therefore, miRNAs serve important roles in the process of regulating cellular activities.

In conclusion, the results of the present study suggested that the miR-338-3p/NOVA1 axis could be a key signaling pathway in regulating the progression of the $\mathrm{RB}$ tumor. Overexpression of miR-338-3p inhibited cell proliferation, migration and invasion, as well as promoted the apoptosis of the RB cells by targeting NOVA1. Understanding the aberrant molecular signaling pathways in RB could be beneficial to develop improved treatments and prevention strategies in a clinical setting. The present study, to determine the molecular characteristics of RB, may theoretically contribute to the potential therapeutic strategies for RB. 


\section{Acknowledgements}

Not applicable.

\section{Funding}

This study was supported by the China Postdoctoral Science Foundation (grant no. 2019M651310), the National Natural Science Foundation of China (grant no. 81671741) and the Excellent Youth Project of The Fourth Affiliated Hospital of Harbin Medical University (grant no. HYDSYYXQN202021).

\section{Availability of data and materials}

The datasets used and/or analyzed during the current study are available from the corresponding author on reasonable request.

\section{Authors' contributions}

SS designed the project, wrote the manuscript and performed the immunohistochemistry experiments. RW performed the western blot analysis and PCR. SY and SL performed the immunohistochemistry, cell proliferation, apoptosis, invasion and migration experiments. LW performed the colony formation experiment and the in vivo experiments. JW was the project leader, was responsible for the design of the project, the revision of the manuscript and performed some of the experiments. SS and JW are responsible for confirming the authenticity of the raw data. All authors read and approved the final manuscript.

\section{Ethics approval and consent to participate}

The animal study was performed in accordance with the Guide for the Care and Use of Laboratory Animals (National Research Council), and was approved by the Institutional Animal Care and Use Committee of Harbin Medical University.

\section{Patient consent for publication}

Not applicable.

\section{Competing interests}

The authors declare that they have no competing interets.

\section{References}

1. Lin FY and Chintagumpala MM: Neonatal retinoblastoma. Clin Perinatol 48: 53-70,2021.

2. Lee $\mathrm{C}$ and Kim JK: Chromatin regulators in retinoblastoma: Biological roles and therapeutic applications. J Cell Physiol 236: 2318-2332, 2021.

3. Fabian ID, Johnson KP, Stacey AW, Sagoo MS and Reddy MA: Focal laser treatment in addition to chemotherapy for retinoblastoma. Cochrane Database Syst Rev 6: CD012366, 2017.

4. Evangelatos G, Fragoulis GE, Koulouri V and Lambrou GI MicroRNAs in rheumatoid arthritis: From pathogenesis to clinical impact. Autoimmun Rev 18: 102391, 2019.

5. Rupaimoole R and Slack FJ: MicroRNA therapeutics: Towards a new era for the management of cancer and other diseases. Nat Rev Drug Discov 16: 203-222, 2017.

6. Dimaras H, Corson TW, Cobrinik D, White A, Zhao J, Munier FL, Abramson DH, Shields CL, Chantada GL, Njuguna F, et al: Retinoblastoma. Nat Rev Dis Primers 1: 15021, 2015.
7. Ha M and Kim VN: Regulation of microRNA biogenesis. Nat Rev Mol Cell Biol 15: 509-524, 2014.

8. Zeng R, Huang J, Sun Y and Luo J: Cell proliferation is induced in renal cell carcinoma through miR-92a-3p upregulation by targeting FBXW7. Oncol Lett 19: 3258-3268, 2020.

9. Wang H, Li X, Li T, Wang L, Wu X, Liu J, Xu Y and Wei W: Multiple roles of microRNA-146a in immune responses and hepatocellular carcinoma. Oncol Lett 18: 5033-5042, 2019.

10. Virga F, Quirico L, Cucinelli S, Mazzone M, Taverna D and Orso F: MicroRNA-mediated metabolic shaping of the tumor microenvironment. Cancers (Basel) 13: 127, 2021.

11. Annese T, Tamma R, De Giorgis M and Ribatti D: microRNAs biogenesis, functions and role in tumor angiogenesis. Front Oncol 10: 581007, 2020

12. Lu L, Wu M, Lu Y,Zhao Z, Liu T, Fu W and Li W: MicroRNA-424 regulates cisplatin resistance of gastric cancer by targeting SMURF1 based on GEO database and primary validation in human gastric cancer tissues. OncoTargets Ther 12: 7623-7636, 2019.

13. Chen Q, Guo SM, Huang HQ, Huang GP, Li Y, Li ZH, Huang R, Xiao L, Fan CR, Yuan Q, et al: Long noncoding RNA SBF2-AS1 contributes to the growth and metastatic phenotypes of NSCLC via regulating miR-338-3p/ADAM17 axis. Aging (Albany NY) 12: 17902-17920, 2020.

14. Liu Z, Liu F, Wang F, Yang X and Guo W: CircZNF609 promotes cell proliferation, migration, invasion, and glycolysis in nasopharyngeal carcinoma through regulating HRAS via miR-338-3p. Mol Cell Biochem 476: 175-186, 2021.

15. Lu H,Zhang Q, Sun Y, Wu D and Liu L: LINC00689 induces gastric cancer progression via modulating the miR-338-3p/HOXA3 axis. J Gene Med 22: e3275, 2020.

16. Buckanovich RJ, Posner JB and Darnell RB: Nova, the paraneoplastic $\mathrm{Ri}$ antigen, is homologous to an RNA-binding protein and is specifically expressed in the developing motor system. Neuron 11: 657-672, 1993.

17. Gumina V, Colombrita C, Fallini C, Bossolasco P, Maraschi AM, Landers JE, Silani V and Ratti A: TDP-43 and NOVA-1 RNA-binding proteins as competitive splicing regulators of the schizophrenia-associated TNIK gene. Biochim Biophys Acta Gene Regul Mech 1862: 194413, 2019.

18. Zhang YA, Liu HN, Zhu JM, Zhang DY, Shen XZ and Liu TT: RNA binding protein Nova1 promotes tumor growth in vivo and its potential mechanism as an oncogene may due to its interaction with GABAA Receptor- $\gamma 2$. J Biomed Sci 23: 71, 2016.

19. Bai S, Tian B, Li A, Yao Q, Zhang G and Li F: MicroRNA-125b promotes tumor growth and suppresses apoptosis by targeting DRAM2 in retinoblastoma. Eye (Lond) 30: 1630-1638, 2016.

20. Jwala J, Vadlapatla RK, Vadlapudi AD, Boddu SH, Pal D and Mitra AK: Differential expression of folate receptor-alpha, sodium-dependent multivitamin transporter, and amino acid transporter $(\mathrm{B}(0,+))$ in human retinoblastoma $(\mathrm{Y}-79)$ and retinal pigment epithelial (ARPE-19) cell lines. J Ocul Pharmacol Ther 28: 237-244, 2012.

21. Wang Q,Zhu Y,Zuo G, Chen X, Cheng J and Zhang S: LINC00858 promotes retinoblastoma cell proliferation, migration and invasion by inhibiting miR-3182. Exp Ther Med 19: 999-1005, 2020.

22. Livak KJ and Schmittgen TD: Analysis of relative gene expression data using real-time quantitative PCR and the 2(-Delta Delta C(T)) method. Methods 25: 402-408, 2001.

23. Yu ACY, Chern YJ, Zhang P, Pasiliao CC, Rahman M, Chang G, Ren J and Tai IT: Inhibition of nucleophosmin 1 suppresses colorectal cancer tumor growth of patient-derived xenografts via activation of $\mathrm{p} 53$ and inhibition of AKT. Cancer Biol Ther 22: 112-123, 2021.

24. Francis JH, Richards AL, Mandelker DL, Berger MF, Walsh MF, Dunkel IJ, Donoghue MT and Abramson DH: Molecular changes in retinoblastoma beyond RB1: Findings from next-generation sequencing. Cancers (Basel) 13: 149, 2021.

25. Guzman F, Fazeli Y, Khuu M, Salcido K, Singh S and Benavente CA: Retinoblastoma tumor suppressor protein roles in epigenetic regulation. Cancers (Basel) 12: 2807, 2020.

26. Zhang $\mathrm{C}$ and $\mathrm{Wu}$ S: microRNA-378a-3p restrains the proliferation of retinoblastoma cells but promotes apoptosis of retinoblastoma cells via inhibition of FOXG1. Invest Ophthalmol Vis Sci 61: 31, 2020.

27. Kashiwa A, Aiba T, Makimoto H, Shimamoto K, Yamagata K, Kamakura T, Wada M, Miyamoto K, Inoue-Yamada Y, Ishibashi K, et al: Systematic evaluation of KCNQ1 variant using ACMG/AMP guidelines and risk stratification in long QT syndrome type 1. Circ Genom Precis Med: Sep 16, 2020 (Epub ahead of print). doi: 10.1161/CIRCGEN.120.002926. 
28. Wang Y and Qin H: miR-338-3p targets RAB23 and suppresses tumorigenicity of prostate cancer cells. Am J Cancer Res 8: 2564-2574, 2018.

29. Wang L, Peng X, Lu X, Wei Q, Chen M and Liu L: Inhibition of hsa_circ_0001313 (circCCDC66) induction enhances the radio-sensitivity of colon cancer cells via tumor suppressor miR-338-3p: Effects of cicr_0001313 on colon cancer radio-sensitivity. Pathol Res Pract 215: 689-696, 2019.

30. Raizis AM, Racher HM, Foucal A, Dimaras H, Gallie BL and George PM: DNA hypermethylation/boundary control loss identified in retinoblastomas associated with genetic and epigenetic inactivation of the RB1 gene promoter. Epigenetics: Dec 1, 2020 (Epub ahead of print). doi: 10.1080/15592294.2020.1834911.

31. Mehyar M, Mosallam M, Tbakhi A, Saab A, Sultan I, Deebajah R, Jaradat I, AlJabari R, Mohammad M, AlNawaiseh I, et al: Impact of RB1 gene mutation type in retinoblastoma patients on clinical presentation and management outcome. Hematol Oncol Stem Cell Ther 13: 152-159, 2020.

32. Sayed ME, Yuan L, Robin JD, Tedone E, Batten K, Dahlson N, Wright WE, Shay JW and Ludlow AT: NOVA1 directs PTBP1 to hTERT pre-mRNA and promotes telomerase activity in cancer cells. Oncogene 38: 2937-2952, 2019.

33. Villate O, Turatsinze JV, Mascali LG, Grieco FA, Nogueira TC, Cunha DA, Nardelli TR, Sammeth M, Salunkhe VA, Esguerra JL, et al: Nova1 is a master regulator of alternative splicing in pancreatic beta cells. Nucleic Acids Res 42: 11818-11830, 2014.
34. Trujillo CA, Rice ES, Schaefer NK, Chaim IA, Wheeler EC, Madrigal AA, Buchanan J, Preissl S, Wang A, Negraes PD, et al: Reintroduction of the archaic variant of NOVA1 in cortical organoids alters neurodevelopment. Science 371: eaax2537, 2021.

35. Kim DY, Choi JA, Koh JY and Yoon YH: Efficacy and safety of aflibercept in in vitro and in vivo models of retinoblastoma. J Exp Clin Cancer Res 35: 171, 2016.

36. Kulkarni AD, van Ginkel PR, Darjatmoko SR, Lindstrom MJ and Albert DM: Use of combination therapy with cisplatin and calcitriol in the treatment of Y-79 human retinoblastoma xenograft model. Br J Ophthalmol 93: 1105-1108, 2009.

37. Liu XM, Li XF and Li JC: MiR-146a functions as a potential tumor suppressor in retinoblastoma by negatively regulate neuro-oncological ventral antigen-1. Kaohsiung J Med Sci: Dec 19, 2020 (Epub ahead of print). doi: 10.1002/kjm2.12337.

38. Xu L, Zhu S, Tang A and Liu W: LncRNA MBLN1-AS1 inhibits the progression of retinoblastoma through targeting miR-338-5p-Wnt/ $\beta$-catenin signaling pathway. Inflamm Res 70: 217-227, 2021

39. Liu H, Yuan HF, Xu D, Chen KJ, Tan N and Zheng QJ: Circular RNA circ_0000034 upregulates STX17 level to promote human retinoblastoma development via inhibiting miR-361-3p. Eur Rev Med Pharmacol Sci 24: 12080-12092, 2020. International (CC BY-NC-ND 4.0) License. 